Article

\title{
Spectrum Analysis and Optimization of the Axial Magnetic Gear with Halbach Permanent Magnet Arrays
}

\author{
Fang Hu ${ }^{1}$, Yilan Zhou ${ }^{1,2}$, Hesong Cui ${ }^{3}$ and Xiao Liu ${ }^{1, *}$ \\ 1 College of Electrical and Information Engineering, Hunan University, Lushan South Road. Yuelu District, \\ Changsha 410082, China; hufang@hnu.edu.cn (F.H.); zy1911234@163.com (Y.Z.) \\ 2 Nanyang Power Supply Company, Electric Power of Henan, State Grid Corporation of China, \\ Nanyang 473000, China \\ 3 Beijing Electrical Research Institute for Technique and Economy MI, No. 188 West Section of South \\ 4th Ring Road, Fengtai District, Beijing 100070, China; 446560663@163.com \\ * Correspondence: xiaoliu@hnu.edu.cn; Tel.: +86-138-6747-7961
}

Received: 30 April 2019; Accepted: 22 May 2019; Published: 25 May 2019

\begin{abstract}
In order to study the contribution of each harmonic to the output torque and axial torque of the axial magnetic gear with Halbach permanent magnet arrays (HAMG), torque and axial force calculation formulas of the HAMG are proposed based on the air-gap flux density distribution of the HAMG. Because of the difference of the air-gap flux densities at different radii, two simplified torque and axial force calculation formulas are proposed and compared. To improve the torque capability of the HAMG, parametric analysis of eight dimensional parameters is firstly conducted. By parametric analysis, six parameters such as the inner radius have been found to have obvious impact on the output torque and output torque density of the HAMG. The optimization using Maxwell software is then executed for maximizing the output torque density of the HAMG. The output torque density of the optimized HAMG is improved from $78.1 \mathrm{kNm} / \mathrm{m}^{3}$ to $93.3 \mathrm{kNm} / \mathrm{m}^{3}$ with an increase of $19 \%$. Furthermore, spectrum analysis is also presented to illustrate the significant output torque improvement based on the torque calculation formulas.
\end{abstract}

Keywords: axial magnetic gear; Halbach; parametric analysis; optimization

\section{Introduction}

Magnetic gears (MGs) have garnered more and more attention due to their potential to offer many advantages over mechanical gears, such as no lubrication, no maintenance, low acoustic noise, high reliability, long lifetime, and inherent overload protection [1,2]. They are particularly attractive for applications desiring a high-speed reduction ratio, such as electric vehicles [3,4] and wind turbines [5].

Since 2001, K. Atallah and D. Howe applied the principle of magnetic field modulation to MGs, different types of MGs [6-8] including the axial magnetic gear (AMG) [9-12] have been proposed. Compared to the coaxial MG, the AMG has not been studied in depth yet, because high axial force may limit the development of the AMG. However, the AMG shows superiority in applications requiring hermetic isolation.

A thorough, parametric comparison of axial and radial flux coaxial magnetic gears with surface-mounted permanent magnets is provided in [13]. A topology for an axial flux magnetically geared machine, in which the electric machine is placed in the bore of the axial flux magnetic gear is proposed in [14]. In [15], an axial-flux modulated superconducting magnetic gear is specifically studied. The torque calculation formula of the coaxial MG is proposed in [16]. The effect of various dimensional parameters of the coaxial MG on the torque capability has been studied [17]. However, 
the torque and axial force calculation formula and the effect of various dimensional parameters on the torque capability of the axial magnetic gear with Halbach permanent magnet arrays (HAMG) have not yet been done.

In this paper, in order to study the contribution of each harmonic to the output torque and axial torque of the HAMG in depth, torque and axial force calculation formulas are proposed based on the air-gap flux densities. Because the air-gap flux densities at different radii of the HAMG are not the same, two simplified torque and axial force calculation formulas are proposed and compared. The influence of eight dimensional parameters on the torque capability of the HAMG is studied by the 3D finite element method (FEM). Meanwhile, in order to maximize the output torque density of the HAMG, an optimization is carried out with the aid of the Maxwell software.

\section{Topologies of the Halbach Permanent Magnet Array (HAMG)}

The topologies of the general AMG and the studied HAMG are shown in Figures 1 and 2, respectively. The difference of the HAMG and the general AMG lies in the magnetization orientations of permanent magnet (PM) pieces. The PMs of the general AMG are axially magnetized, while the HAMG has different orientations of PM pieces. It is well known that Halbach PM arrays hold the attractive features of sinusoidal flux density distribution in the air gap, strong field intensity and good self-shielding magnetization. Therefore, the HAMG is characterized by high stall torque, low torque ripples and iron losses compared with the general AMG.

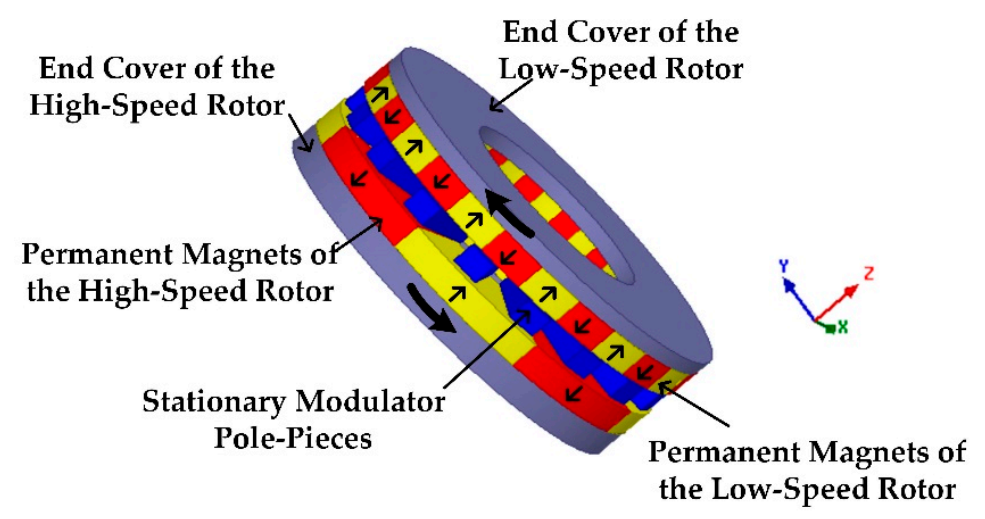

Figure 1. Topology of the general axial magnetic gear (AMG).

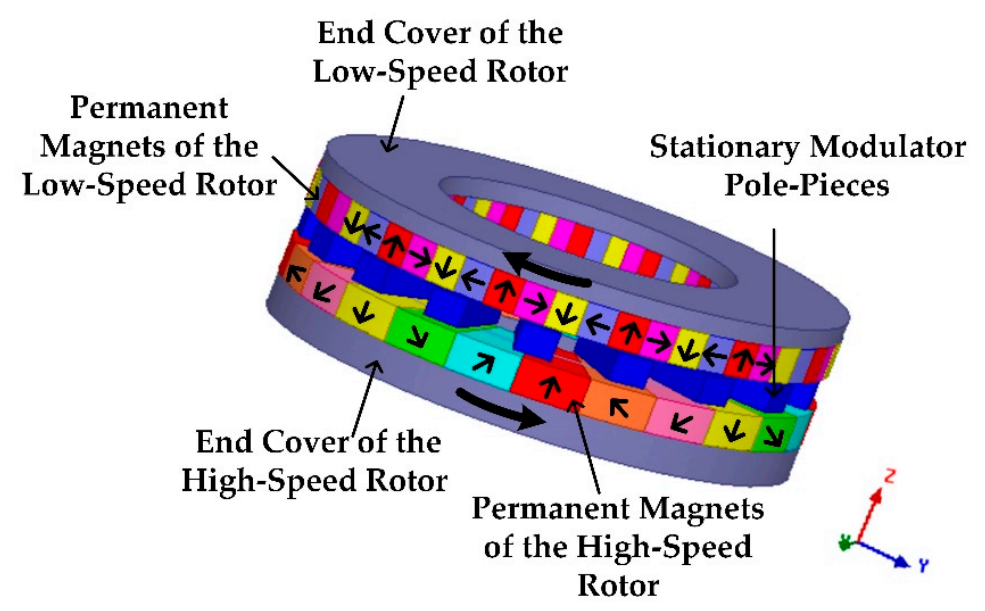

Figure 2. Topology of the axial magnetic gear with Halbach permanent magnet array (HAMG).

The HAMG is composed of three parts, namely, the high-speed rotor, the low-speed rotor, and the stationary modulator ring sandwiched between the two rotors. The stationary modulator ring takes charge of modulating the magnetic field in two air gaps beside it. Halbach PM arrays, which are capable 
of augmenting the magnetic flux in the air gap while suppressing that in the end cover, are adopted for both the two rotors of the studied HAMG. Thus, the two end covers of the HAMG could be made of non-magnetic material instead of iron.

The numbers of PM pole-pairs on the high-speed rotor and the low-speed rotor are, respectively, 4 and 13, resulting a theoretical gear ratio of 3.25, and the number of the modulator pieces is 17 . There are $3 \mathrm{PM}$ pieces composing each pole for the high-speed rotor, and $2 \mathrm{PM}$ pieces per pole for the low-speed rotor. Rectangular shaped modulator pole-pieces are adopted for convenient lamination process. Table 1 gives the key dimensional parameters and their initial values for the HAMG.

Table 1. Key parameters of the HAMG.

\begin{tabular}{cc}
\hline Description & Value \\
\hline axial thickness of PMs on the high-speed rotor, $T_{\mathrm{h}}(\mathrm{mm})$ & 10 \\
axial thickness of PMs on the low-speed rotor, $T_{1}(\mathrm{~mm})$ & 10 \\
axial thickness of end cover on the high-speed rotor $(\mathrm{mm})$ & 10 \\
axial thickness of end cover on the low-speed rotor $(\mathrm{mm})$ & 5.5 \\
axial thickness of rectangular shape modulation pieces, $T_{\mathrm{m}}(\mathrm{mm})$ & 8 \\
inner radius, $R_{\text {out }}(\mathrm{mm})$ & 40 \\
outer radius, $R_{\text {in }}(\mathrm{mm})$ & 70 \\
axial thickness of air-gaps $(\mathrm{mm})$ & 1 \\
length of rectangular shape modulation pieces, $L_{\mathrm{m}}(\mathrm{mm})$ & 27 \\
width of rectangular shape modulation pieces, $W_{\mathrm{m}}(\mathrm{mm})$ & 10 \\
mechanical angle of each axially magnetized PMs on the high-speed rotor, $\theta_{\mathrm{h}}\left(^{\circ}\right)$ & 15 \\
mechanical angle of each axially magnetized PMs on the low-speed rotor, $\theta_{1}\left(^{\circ}\right)$ & 6.92 \\
PM material & NdFeB35 \\
material of stationary modulator pole-pieces & DW360_50 \\
\hline
\end{tabular}

\section{Formulas for Calculating Torque and Axial Force of the Axial Magnetic Gear with Halbach Permanent Magnet Array (HAMG)}

The interaction of the space harmonics is the reason for the torque production. It could be shown that the number of pole-pairs in the air-gap flux density produced by either the high-speed or low-speed rotor PMs, is given by,

$$
\begin{gathered}
p_{m, k}=\left|m p+k n_{\mathrm{s}}\right| \\
m=1,3,5, \ldots, \infty \\
k=0, \pm 1, \pm 2, \pm 3, \ldots, \pm \infty
\end{gathered}
$$

where $p$ is the number of pole-pairs on PM rotor, and $n_{\mathrm{s}}$ is the number of the ferromagnetic modulator pole-pieces.

The air-gap flux density of the HAMG includes not only the radial component, the tangential component, but also the axial component. The axial flux density is the most important component of the air-gap flux density, which has the greatest influence on the torque capability of the HAMG. The tangential flux density also has some effect on the torque capability of the HAMG. However, the torque capability of the HAMG is independent of the radial flux density.

The torque and axial force of the HAMG are calculated by the Maxwell stress tensor based on the air-gap flux density distribution,

$$
\begin{gathered}
T=\frac{\left(R_{\text {out }}^{2}-R_{\text {in }}^{2}\right)}{2 \mu_{0}} \int_{R_{\text {in }}}^{R_{\text {out }}} \int_{0}^{2 \pi} B_{z}(z, r, \theta) B_{\theta}(z, r, \theta) d \theta d r \\
F=\frac{\left(R_{\text {out }}-R_{\text {in }}\right)}{2 \mu_{0}} \int_{R_{\text {in }}}^{R_{\text {out }}} \int_{0}^{2 \pi}\left(B_{z}^{2}(z, r, \theta)-B_{\theta}^{2}(z, r, \theta)\right) d \theta d r
\end{gathered}
$$


where $\mu_{0}$ is the vacuum permeability, $B_{z}(z, r, \theta)$ is the axial flux density and $B_{\theta}(z, r, \theta)$ is the tangential flux density. The air-gap flux densities at different radii are not the same. There is no way to superimpose $\int_{0}^{2 \pi} B_{z}(z, r, \theta) B_{\theta}(z, r, \theta) d \theta$ and $\int_{0}^{2 \pi}\left(B_{z}^{2}(z, r, \theta)-B_{\theta}^{2}(z, r, \theta)\right) d \theta$ at all radii of the air gap, respectively. Therefore, two simplified torque and axial force calculation methods are proposed to calculate the torque and axial force of the HAMG.

The first simplified torque and axial force calculation method is to replace the air-gap flux densities at different radii with the air-gap flux density at the mean radius $R_{\mathrm{m}}$, where $R_{\mathrm{m}}=\left(R_{\text {in }}+R_{\text {out }}\right) / 2$. Therefore, the formulas for the torque and axial force of the HAMG by the first simplified method could be converted as,

$$
\begin{gathered}
T=\frac{\left(R_{\text {out }}^{2}-R_{\mathrm{in}}^{2}\right) R_{\mathrm{m}}}{2 \mu_{0}} \int_{0}^{2 \pi} B_{z}\left(z, R_{\mathrm{m}}, \theta\right) B_{\theta}\left(z, R_{\mathrm{m}}, \theta\right) d \theta \\
F=\frac{\left(R_{\text {out }}-R_{\mathrm{in}}\right) R_{\mathrm{m}}}{2 \mu_{0}} \int_{0}^{2 \pi}\left(B_{z}^{2}\left(z, R_{\mathrm{m}}, \theta\right)-B_{\theta}^{2}\left(z, R_{\mathrm{m}}, \theta\right)\right) d \theta
\end{gathered}
$$

The expressions of the axial flux density $B_{z}(z, r, \theta)$ and the tangential flux density $B_{\theta}(z, r, \theta)$ are as follows,

$$
\begin{aligned}
& B_{z}(z, r, \theta)=\sum_{n=1,2,3}^{+\infty} b_{z}^{n}(z, r) \cos \left(n \theta-\varphi_{z}^{n}\right) \\
& B_{\theta}(z, r, \theta)=\sum_{n=1,2,3}^{+\infty} b_{\theta}^{n}(z, r) \cos \left(n \theta-\varphi_{\theta}^{n}\right)
\end{aligned}
$$

where $b_{z}^{n}$ and $b_{\theta}^{n}$ are the magnitude of Fourier coefficients, $\varphi_{z}^{n}$ and $\varphi_{\theta}^{n}$ are the initial angles of the axial and tangential flux density distribution. The expressions of the axial flux density $B_{z}\left(z, R_{\mathrm{m}}, \theta\right)$ and the tangential flux density $B_{\theta}\left(z, R_{\mathrm{m}}, \theta\right)$ at the mean radius $R_{\mathrm{m}}$ are as follows,

$$
\begin{aligned}
& B_{z}\left(z, R_{\mathrm{m}}, \theta\right)=\sum_{n=1,2,3}^{+\infty} b_{z}^{n}\left(z, R_{\mathrm{m}}\right) \cos \left(n \theta-\varphi_{z}^{n}\right) \\
& B_{\theta}\left(z, R_{\mathrm{m}}, \theta\right)=\sum_{n=1,2,3}^{+\infty} b_{\theta}^{n}\left(z, R_{\mathrm{m}}\right) \cos \left(n \theta-\varphi_{\theta}^{n}\right)
\end{aligned}
$$

Substituting Equations (8) and (9) into Equations (4) and (5), respectively. Equations (4) and (5) could be transformed as,

$$
\begin{gathered}
T=\frac{\pi\left(R_{\text {out }}^{2}-R_{\text {in }}^{2}\right) R_{\mathrm{m}}}{2 \mu_{0}} \sum_{n=1,2,3}^{+\infty} b_{z}^{n}\left(z, R_{\mathrm{m}}\right) b_{\theta}^{n}\left(z, R_{\mathrm{m}}\right) \cos \left(\varphi_{z}^{n}-\varphi_{\theta}^{n}\right) \\
F=\frac{\pi\left(R_{\mathrm{out}}-R_{\mathrm{in}}\right) R_{\mathrm{m}}}{2 \mu_{0}} \sum_{n=1,2,3}^{+\infty}\left[\left(b_{z}^{n}\left(z, R_{\mathrm{m}}\right)\right)^{2}-\left(b_{\theta}^{n}\left(z, R_{\mathrm{m}}\right)\right)^{2}\right]
\end{gathered}
$$

It can be found that only the interaction between the axial and tangential flux density components with the same pole-pair number could contribute to the torque and axial force. From (10) and (11), it can be found that the amplitudes of the axial and tangential flux densities of $n$ th-order harmonic at the mean radius as well as their phase difference are critical to the torque production. However, the axial force of the HAMG is only related to the squared difference of amplitudes of the axial and tangential flux densities of $n$ th-order harmonic at the mean radius.

The first simplified torque and axial force calculation method only consider the air-gap flux density at the mean radius, but do not consider that the air-gap flux densities at different radii of the 
HAMG are not the same. Moreover, the air-gap flux densities near the inner and outer radius are significantly reduced because of flux leakage. Therefore, a second simplified torque and axial force calculation method is proposed to calculate the torque and axial force of the HAMG.

Firstly, the air-gap flux densities at different radii in the air gap adjacent to the low-speed rotor (LG) of the HAMG are studied. The 13th order harmonic contribution to output torque is much larger than other harmonics. The inner radius of the air gap is $40 \mathrm{~mm}$ and the outer radius of the air gap is $70 \mathrm{~mm}$. The air gap is divided into 30 parts according to the radius and each one is $1 \mathrm{~mm}$. Draw circles at different radii, obtain the air-gap flux densities at different radii, perform the fast Fourier transformation (FFT) on the air-gap flux densities at different radii and obtain the amplitudes of the axial and tangential flux densities of 13th-order harmonic as well as their phase differences at different radii. Table 2 lists the amplitudes and their phase differences of the axial and tangential flux densities of 13th-order harmonics at different radii in the LG of the HAMG, respectively.

Table 2. Amplitudes and their phase differences of the axial and tangential flux densities of 13th-order harmonics at different radii.

\begin{tabular}{cccccccc}
\hline Radius/mm & $\boldsymbol{b}_{\boldsymbol{z}}^{13} / \mathbf{T}$ & $\boldsymbol{b}_{\boldsymbol{\theta}}^{13} / \mathbf{T}$ & $\boldsymbol{\varphi}_{\boldsymbol{z}}^{13}-\boldsymbol{\varphi}_{\boldsymbol{\theta}}^{13} /^{\circ}$ & Radius/mm & $\boldsymbol{b}_{\boldsymbol{z}}^{13} / \mathbf{T}$ & $\boldsymbol{b}_{\boldsymbol{\theta}}^{13} / \mathbf{T}$ & $\boldsymbol{\varphi}_{\boldsymbol{z}}^{13}-\boldsymbol{\varphi}_{\boldsymbol{\theta}}^{13} /^{\circ}$ \\
\hline 41 & 0.850 & 0.430 & 53.3 & 56 & 1.28 & 0.489 & 66.1 \\
42 & 1.26 & 0.441 & 43.2 & 57 & 1.26 & 0.492 & 66.9 \\
43 & 1.41 & 0.432 & 43.0 & 58 & 1.25 & 0.493 & 67.9 \\
44 & 1.39 & 0.439 & 46.3 & 59 & 1.25 & 0.494 & 68.9 \\
45 & 1.40 & 0.445 & 48.5 & 60 & 1.23 & 0.493 & 69.7 \\
46 & 1.39 & 0.451 & 52.1 & 61 & 1.22 & 0.491 & 70.5 \\
47 & 1.38 & 0.457 & 52.6 & 62 & 1.20 & 0.486 & 71.2 \\
48 & 1.37 & 0.461 & 54.3 & 63 & 1.19 & 0.482 & 71.6 \\
49 & 1.36 & 0.464 & 56.1 & 64 & 1.16 & 0.480 & 71.9 \\
50 & 1.35 & 0.469 & 57.9 & 65 & 1.13 & 0.467 & 72.7 \\
51 & 1.34 & 0.476 & 59.6 & 66 & 1.11 & 0.456 & 72.5 \\
52 & 1.33 & 0.478 & 61.3 & 67 & 1.06 & 0.436 & 72.3 \\
53 & 1.32 & 0.482 & 62.2 & 68 & 0.997 & 0.411 & 71.3 \\
54 & 1.30 & 0.485 & 63.4 & 69 & 0.830 & 0.374 & 69.5 \\
55 & 1.29 & 0.491 & 64.6 & & & & \\
\hline
\end{tabular}

Table 2 shows that the amplitudes of the axial and tangential flux densities of 13th-order harmonics as well as their differences at different radii vary from $0.830 \mathrm{~T}$ to $1.41 \mathrm{~T}, 0.374 \mathrm{~T}$ to $0.494 \mathrm{~T}$ and $43.0^{\circ}$ to $72.7^{\circ}$, respectively.

For the amplitude of the axial flux density of 13th-order harmonic $b_{z}^{13}$, the amplitude of the tangential flux density of 13th-order harmonic $b_{\theta}^{13}$ and the cosine value of their phase difference of the axial and tangential flux densities of 13th-order harmonic $\cos \left(\varphi_{z}^{13}-\varphi_{\theta}^{13}\right)$, the impact of $b_{z}^{13}$ on the output torque and axial force of the HAMG is greater than $b_{\theta}^{13}$ and $\cos \left(\varphi_{z}^{13}-\varphi_{\theta}^{13}\right)$. Therefore, the second simplified calculation method for calculating the torque and axial force of the HAMG is to divide the LG into five parts according to the variation rule of $b_{z}^{13}$ at different radii, as shown in Figure 3. Each color represents a part of the LG. The torque and axial force generated by the five parts are superposed to be the torque and axial force generated by the entire HAMG, respectively. The 1st part is from $R_{\text {out } 0}$ $=40 \mathrm{~mm}$ to $R_{\text {out } 1}=42 \mathrm{~mm}$, the 2 nd part is from $R_{\text {out } 1}=42 \mathrm{~mm}$ to $R_{\text {out } 2}=50 \mathrm{~mm}$, the 3 rd part is from $R_{\text {out } 2}=50 \mathrm{~mm}$ to $R_{\text {out } 3}=60 \mathrm{~mm}$, the 4 th part is from $R_{\text {out } 3}=60 \mathrm{~mm}$ to $R_{\text {out } 4}=68 \mathrm{~mm}$ and the 5 th part is from $R_{\text {out } 4}=68 \mathrm{~mm}$ to $R_{\text {out } 5}=70 \mathrm{~mm}$.

According to Equations (2) and (3), the expressions of the torque and axial force generated by the $i$ th $(i=1,2,3,4,5)$ part are as follows,

$$
T_{i}=\frac{\left(R_{\text {out } i}^{2}-R_{\text {out } i-1}^{2}\right)}{2 \mu_{0}} \int_{R_{\text {out } i-1}}^{R_{\text {out } i}} \int_{0}^{2 \pi} B_{z}(z, r, \theta) B_{\theta}(z, r, \theta) d \theta d r
$$




$$
F_{i}=\frac{\left(R_{\text {out } i}-R_{\text {out } i-1}\right)}{2 \mu_{0}} \int_{R_{\text {out }-1}}^{R_{\text {out }}} \int_{0}^{2 \pi}\left(B_{z}^{2}(z, r, \theta)-B_{\theta}^{2}(z, r, \theta)\right) d \theta d r
$$

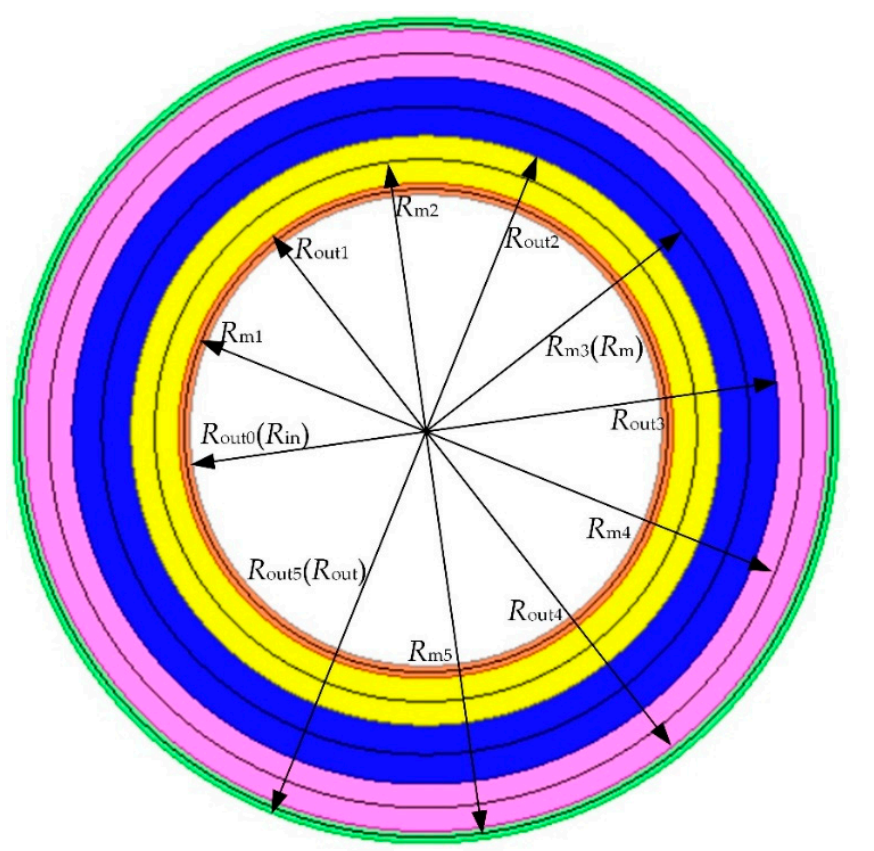

Figure 3. Air-gap separation diagram.

The air-gap flux densities at different radii of the $i$ th part are replaced by the air-gap flux density at the mean radius $R_{\mathrm{m} i}$ of the $i$ th part, where $R_{\mathrm{m} i}=\left(R_{\mathrm{out} i}+R_{\mathrm{out} i-1}\right) / 2$. Therefore, the expressions of the torque and axial force generated by the $i$ th part could be converted as,

$$
\begin{gathered}
T_{i}=\frac{\left(R_{\text {out } i}^{2}-R_{\text {out } i-1}^{2}\right) R_{\mathrm{m} i}}{2 \mu_{0}} \int_{0}^{2 \pi} B_{z}\left(z, R_{\mathrm{m} i}, \theta\right) B_{\theta}\left(z, R_{\mathrm{m} i}, \theta\right) d \theta \\
F_{i}=\frac{\left(R_{\mathrm{out} i}-R_{\mathrm{out} i-1}\right) R_{\mathrm{m} i}}{2 \mu_{0}} \int_{0}^{2 \pi}\left(B_{z}^{2}\left(z, R_{\mathrm{m} i}, \theta\right)-B_{\theta}^{2}\left(z, R_{\mathrm{m} i}, \theta\right)\right) d \theta
\end{gathered}
$$

The expressions of the axial and tangential flux densities at the mean radius $R_{\mathrm{m} i}$ of the $i$ th part are as follows,

$$
\begin{aligned}
& B_{z}\left(z, R_{\mathrm{m} i}, \theta\right)=\sum_{n=1,2,3}^{+\infty} b_{z}^{n}\left(z, R_{\mathrm{m} i}\right) \cos \left(n \theta-\varphi_{z}^{n}\right) \\
& B_{\theta}\left(z, R_{\mathrm{m} i}, \theta\right)=\sum_{n=1,2,3}^{+\infty} b_{\theta}^{n}\left(z, R_{\mathrm{m} i}\right) \cos \left(n \theta-\varphi_{\theta}^{n}\right)
\end{aligned}
$$

Substituting Equations (16) and (17) into Equations (14) and (15), Equations (14) and (15) could be transformed as,

$$
\begin{gathered}
T_{i}=\frac{\pi\left(R_{\text {out } i}^{2}-R_{\text {out } i-1}^{2}\right) R_{\mathrm{m} i}}{2 \mu_{0}} \sum_{n=1,2,3}^{+\infty} b_{z}^{n}\left(z, R_{\mathrm{m} i}\right) b_{\theta}^{n}\left(z, R_{\mathrm{m} i}\right) \cos \left(\varphi_{z}^{n}-\varphi_{\theta}^{n}\right) \\
F_{i}=\frac{\pi\left(R_{\text {out } i}-R_{\text {out } i-1}\right) R_{\mathrm{m} i}}{2 \mu_{0}} \sum_{n=1,2,3}^{+\infty}\left[\left(b_{z}^{n}\left(z, R_{\mathrm{m} i}\right)\right)^{2}-\left(b_{\theta}^{n}\left(z, R_{\mathrm{m} i}\right)\right)^{2}\right]
\end{gathered}
$$


Table 3 lists the amplitudes and their phase differences of the axial and tangential flux densities of dominating harmonics at the radii of $R_{\mathrm{m} 1}, R_{\mathrm{m} 2}, R_{\mathrm{m} 3}, R_{\mathrm{m} 4}$ and $R_{\mathrm{m} 5}$ in the HAMG, respectively.

Table 3. Axial and tangential flux densities at the radii of $R_{\mathrm{m} 1}, R_{\mathrm{m} 2}, R_{\mathrm{m} 3}, R_{\mathrm{m} 4}$ and $R_{\mathrm{m} 5}$ in the HAMG and their phase differences.

\begin{tabular}{lccccccc}
\hline \multirow{2}{*}{ Harmonic Order } & \multicolumn{3}{c}{$\boldsymbol{P}_{\mathbf{h}}$} & \multicolumn{3}{c}{$\boldsymbol{P}_{\mathbf{1}}$} \\
\cline { 3 - 8 } & & \multicolumn{3}{c}{ 4th } & \multicolumn{1}{c}{ 13th } \\
\cline { 3 - 8 } & & $\boldsymbol{b}_{z}^{4} / \mathbf{T}$ & $\boldsymbol{b}_{\theta}^{4} / \mathbf{T}$ & $\boldsymbol{\varphi}_{z}^{4}-\boldsymbol{\varphi}_{\theta}^{4} /{ }^{\circ}$ & $\boldsymbol{b}_{z}^{13} / \mathbf{T}$ & $\boldsymbol{b}_{\boldsymbol{\theta}}^{13} / \mathbf{T}$ & $\boldsymbol{\varphi}_{z}^{13}-\boldsymbol{\varphi}_{\theta}^{13}{ }^{\circ}$ \\
\hline \multirow{2}{*}{$R_{\mathrm{m} 1}$} & HG & 0.491 & 0.343 & 116 & 0.159 & 0.121 & 85.6 \\
& LG & 0.279 & 0.241 & 82.4 & 0.858 & 0.432 & 53.3 \\
\hline \multirow{2}{*}{$R_{\mathrm{m} 2}$} & HG & 0.908 & 0.351 & 117 & 0.171 & 0.159 & 94.6 \\
& LG & 0.332 & 0.259 & 82.1 & 1.39 & 0.448 & 52.1 \\
\hline \multirow{2}{*}{$R_{\mathrm{m} 3}$} & HG & 0.849 & 0.311 & 108 & 0.0899 & 0.0801 & 97.4 \\
& LG & 0.228 & 0.198 & 89.6 & 1.29 & 0.489 & 64.6 \\
\hline \multirow{2}{*}{$R_{\mathrm{m} 4}$} & HG & 0.747 & 0.273 & 103 & 0.082 & 0.0698 & 82.3 \\
& LG & 0.172 & 0.169 & 76.9 & 1.16 & 0.481 & 71.9 \\
\hline \multirow{2}{*}{$R_{\mathrm{m} 5}$} & HG & 0.451 & 0.223 & 105 & 0.111 & 0.0701 & 102 \\
& LG & 0.169 & 0.151 & 83.4 & 0.841 & 0.369 & 69.5 \\
\hline
\end{tabular}

Table 4 lists the torque generated by 4 th- and 13th-order harmonics at the radius of $R_{\mathrm{m}}$ in the HAMG calculated by the first simplified torque calculation method. Table 4 lists the torque generated by 4 th- and 13 th-order harmonics at the radii of $R_{\mathrm{m} 1}, R_{\mathrm{m} 2}, R_{\mathrm{m} 3}, R_{\mathrm{m} 4}$ and $R_{\mathrm{m} 5}$ in the HAMG calculated by the second simplified torque calculation method, respectively. In order to make the results more accurate, Table 4 also lists the total torque generated by other harmonics except for 4 thand 13th-order harmonics.

Table 4. Torque at different radii by the first or second simplified torque calculation method.

\begin{tabular}{|c|c|c|c|c|c|c|}
\hline \multirow{2}{*}{ Method } & \multirow{2}{*}{\multicolumn{2}{|c|}{ Harmonic Order }} & \multicolumn{4}{|c|}{ Torque/Nm } \\
\hline & & & 4 th & 13th & Other & Sum \\
\hline \multirow{2}{*}{$\begin{array}{l}\text { The first simplified torque } \\
\text { calculation method }\end{array}$} & \multirow{2}{*}{$R_{\mathrm{m}}$} & HG & -18.7 & -0.221 & -0.124 & -19.0 \\
\hline & & LG & 0.0804 & 61.1 & -0.112 & 61.1 \\
\hline \multirow{10}{*}{$\begin{array}{l}\text { The second simplified } \\
\text { torque calculation method }\end{array}$} & \multirow{2}{*}{$R_{\mathrm{m} 1}$} & HG & -0.612 & 0.0101 & 0.0211 & -0.581 \\
\hline & & LG & 0.0701 & 1.85 & 0.01020 & 1.93 \\
\hline & \multirow{2}{*}{$R_{\mathrm{m} 2}$} & HG & -6.08 & -0.0823 & -0.141 & -6.30 \\
\hline & & LG & 0.0421 & 16.2 & -0.122 & 16.2 \\
\hline & \multirow{2}{*}{$R_{\mathrm{m} 3}$} & HG & -6.24 & -0.0812 & -0.0402 & -6.36 \\
\hline & & LG & 0.0311 & 20.4 & -0.0398 & 20.4 \\
\hline & \multirow{2}{*}{$R_{\mathrm{m} 4}$} & HG & -3.68 & 0.0611 & -0.0101 & -3.63 \\
\hline & & LG & 0.531 & 14.0 & 0.111 & 14.6 \\
\hline & \multirow{2}{*}{$R_{\mathrm{m} 5}$} & HG & -0.642 & -0.0398 & 0.0198 & -0.662 \\
\hline & & LG & 0.0734 & 2.59 & 0.0647 & 2.73 \\
\hline
\end{tabular}

It can be seen from Table 4 that the torque generated by 4 th-order harmonic is much larger than that of other harmonics in the air gap adjacent to the high-speed rotor (HG), while the torque generated by 13th-order harmonic is much greater than that of other harmonics in the LG. The output torque of the HAMG calculated by the 3D FEM is $54.7 \mathrm{Nm}$. The output torque of the HAMG calculated by the first simplified torque calculation method is $61.1 \mathrm{Nm}$, which has $12 \%$ increase over the HAMG calculated by the 3D FEM. The output torque of the HAMG calculated by the second simplified torque calculation method is $55.8 \mathrm{Nm}$, which is $2.0 \%$ larger than that obtained by the 3D FEM. 
Table 5 lists the axial force generated by 4 th- and 13th-order harmonics at the radius of $R_{\mathrm{m}}$ in the HAMG by the first simplified axial force calculation method. Table 5 lists the axial force generated by 4 th- and 13th-order harmonics at the radii of $R_{\mathrm{m} 1}, R_{\mathrm{m} 2}, R_{\mathrm{m} 3}, R_{\mathrm{m} 4}$ and $R_{\mathrm{m} 5}$ in the HAMG calculated by the second simplified axial force calculation method, respectively. As with the torque calculation, Table 5 also lists the total axial force generated by other harmonics except for the 4 th- and 13th-order harmonics.

Table 5. Axial force at different radii by the first or second simplified axial force calculation method.

\begin{tabular}{|c|c|c|c|c|c|c|}
\hline \multirow{2}{*}{ Method } & \multirow{2}{*}{\multicolumn{2}{|c|}{ Harmonic Order }} & \multicolumn{4}{|c|}{ Axial Force/N } \\
\hline & & & 4th & 13th & Other & Sum \\
\hline \multirow{2}{*}{$\begin{array}{l}\text { The first simplified axial } \\
\text { force calculation method }\end{array}$} & \multirow{2}{*}{$R_{\mathrm{m}}$} & HG & 1298 & 4 & 62 & 1364 \\
\hline & & LG & 21 & 2955 & 30 & 3006 \\
\hline \multirow{10}{*}{$\begin{array}{l}\text { The second simplified axial } \\
\text { force calculation method }\end{array}$} & \multirow{2}{*}{$R_{\mathrm{m} 1}$} & HG & 12.3 & 1.20 & 0.900 & 14.4 \\
\hline & & LG & 2.20 & 56.6 & 0 & 58.8 \\
\hline & \multirow{2}{*}{$R_{\mathrm{m} 2}$} & $\mathrm{HG}$ & 327 & 4.40 & 18.7 & 350 \\
\hline & & LG & 20.3 & 797 & 11.6 & 829 \\
\hline & \multirow{2}{*}{$R_{\mathrm{m} 3}$} & HG & 433 & 1.30 & 20.7 & 455 \\
\hline & & LG & 7 & 985 & 10 & 1002 \\
\hline & \multirow{2}{*}{$R_{\mathrm{m} 4}$} & HG & 314 & 1.40 & 22.6 & 338 \\
\hline & & LG & 1.10 & 716 & 19.9 & 737 \\
\hline & \multirow{2}{*}{$R_{\mathrm{m} 5}$} & HG & 26.5 & 1 & 4 & 31.5 \\
\hline & & LG & 0.800 & 97.3 & 3.2 & 101 \\
\hline
\end{tabular}

The axial force on the low-speed rotor of the HAMG obtained by the 3D FEM is $2750 \mathrm{~N}$. The axial force on the low-speed rotor of the HAMG obtained by the first simplified axial force calculation method is $3006 \mathrm{~N}$, which has a $9.3 \%$ increase over the HAMG by the 3D FEM. The axial force on the low-speed rotor of the HAMG obtained by the second simplified axial force calculation method is $2728 \mathrm{~N}$, which is $0.80 \%$ smaller than that obtained by the 3D FEM.

The air-gap flux densities of the HAMG at different radii are not the same and the air-gap flux densities near the inner and outer radius are significantly reduced due to flux leakage, which may explain why the output torque and axial force of the HAMG obtained by the first simplified calculation method are greater than those calculated by the 3D FEM. The output torque and axial force of the HAMG calculated by the second simplified calculation method are very close to those calculated by the 3D FEM. Therefore, the accuracy of the second simplified calculation method is much higher than the first simplified calculation method. Of course, the finer the air gap is divided, the closer the final calculated torque and axial force of the HAMG are to the actual values of torque and axial force of the HAMG. However, the finer the air gap is divided, the greater the workload is. Therefore, it is reasonable to divide the air gap into five parts.

\section{Parametric Analysis of the HAMG}

There are various dimensional parameters indicated in Figure 4 affecting the torque capability of the HAMG, including the axial thicknesses on the high-speed rotor $T_{\mathrm{h}}$ and on the low-speed rotor $T_{1}$, the inner radius $R_{\mathrm{in}}$, the thickness of the rectangular shape modulation pieces $T_{\mathrm{m}}$, the length $L_{\mathrm{m}}$ and width $W_{\mathrm{m}}$ of the rectangular shape modulation pieces, the mechanical angle of each axially magnetized PMs on the high-speed rotor $\theta_{\mathrm{h}}$ and that on the low-speed rotor $\theta_{1}$. In order to analyze the influence of each individual parameter, when one parameter is changed, other parameters are kept with the initial values shown in Table 1 . The influence of each parameter on the output torque and output torque density is illustrated in detail in the following section. 


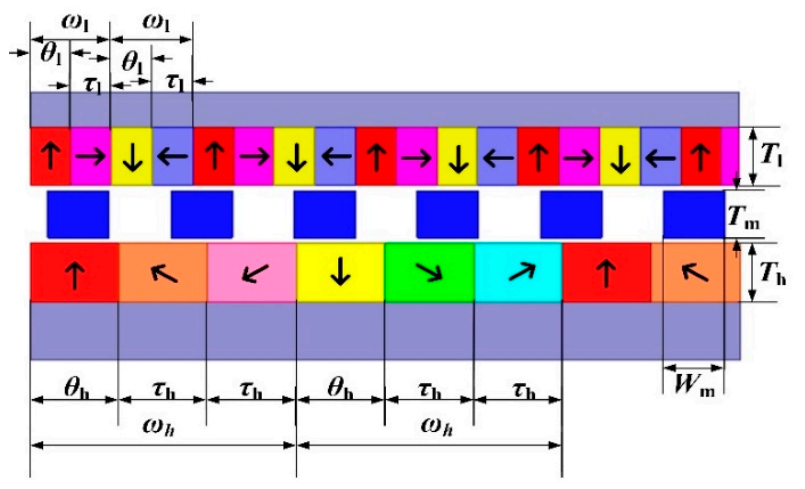

Figure 4. The dimensions of the HAMG.

\subsection{The Influence of the Axial PMs Thickness of the Two Rotors}

Figure $5 \mathrm{a}, \mathrm{b}$ show the curves of the output torque and output torque density versus $T_{\mathrm{h}}$ and $T_{1}$, respectively. It can be seen that the output torque will increase with the growth of $T_{\mathrm{h}}$ and $T_{1}$, but the rate of increase is decreasing gradually. As a result, it is clear that increasing the axial thickness of PMs does not always help to increase the output torque density. This is because the magnetic field of the HAMG may gradually saturate with the growth of the axial thickness of PMs, which means the growth rate of the magnetic field in air gap is lower than that of the PM thicknesses after magnetic field saturation. As could be seen from Figure 5, the output torque density firstly increases with the growth of $T_{\mathrm{h}}$ and $T_{1}$ before saturation and then deceases as saturation occurs. Figure $5 \mathrm{a}$ shows that the output torque density achieves the maximum value when $T_{\mathrm{h}}$ is approximately $21 \mathrm{~mm}$ for the HAMG studied, while the optimal value of $T_{1}$ is approximately $11 \mathrm{~mm}$ as shown in Figure $5 \mathrm{~b}$.
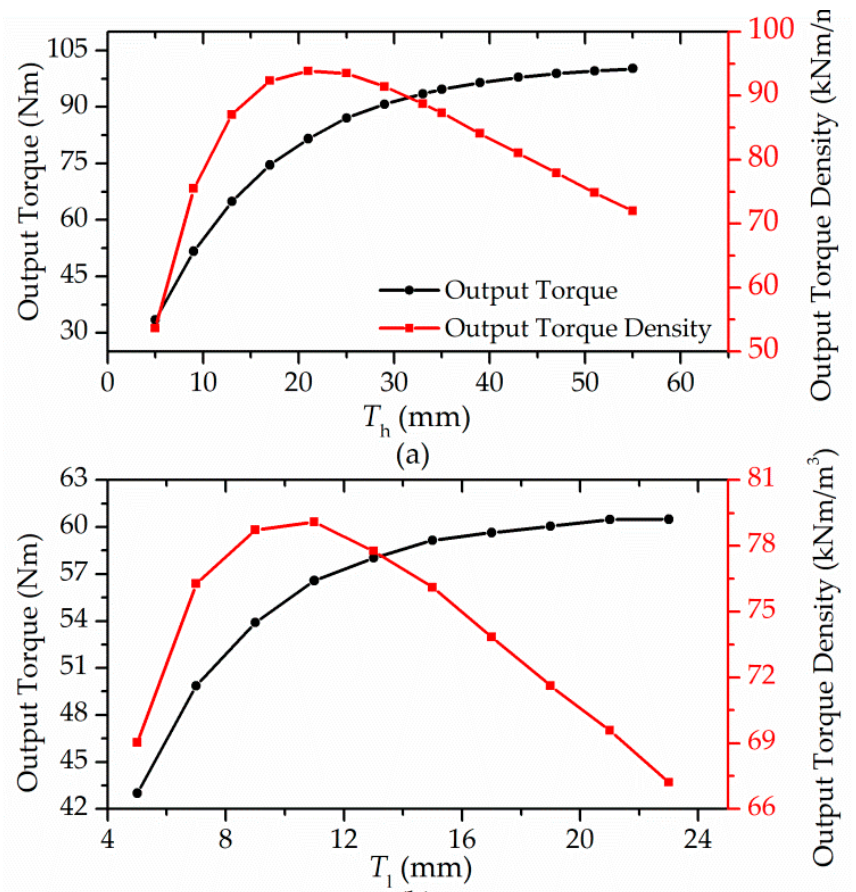

Figure 5. Output torque and output torque density curves versus $T_{\mathrm{h}}$ and $T_{1}$. (a) Axial thickness of PMs on the high-speed rotor; (b) Axial thickness of PMs on the low-speed rotor.

\subsection{The Influence of the Size of the Rectangular Shape Modulation Pieces}

Figure 6 shows the variation of the output torque and output torque density with the axial thickness of the rectangular shape modulation pieces $T_{\mathrm{m}}$. It is obvious that the trend of the two curves 
is similar. Although a $4 \mathrm{~mm}$ thick rectangular shape modulation pieces may help to achieve the highest torque density, the mechanical stiffness of the modulator ring must be taken into account in practice. $T_{\mathrm{m}}$ is designed as $8 \mathrm{~mm}$ in the studied case to guarantee mechanical stiffness.

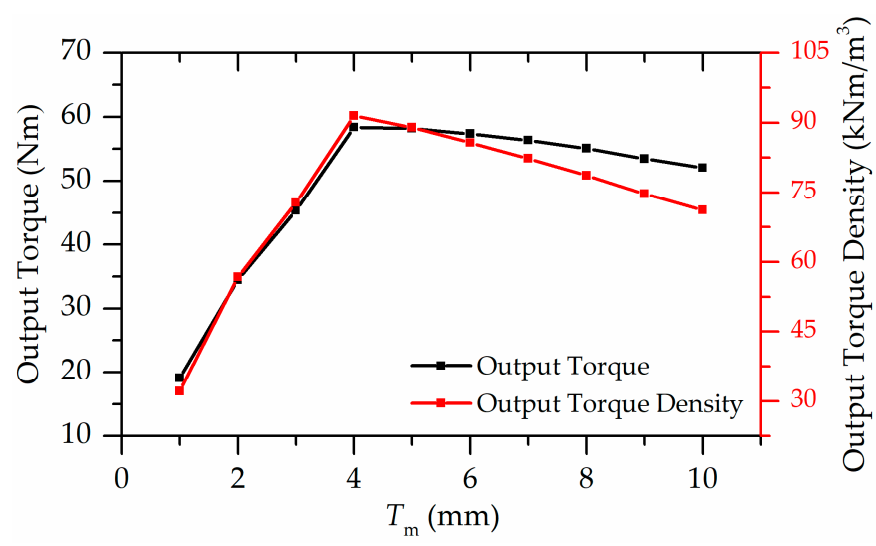

Figure 6. Output torque and output torque density curves versus $T_{\mathrm{m}}$.

When $L_{\mathrm{m}}$ and $W_{\mathrm{m}}$ are varied, the volume of the HAMG remains the same. Therefore, the trend of the curves of the output torque and output torque density will be completely the same as these two parameters are changed. Therefore, only the output torque density is considered for these two parametric analysis.

Figure 7 shows the curves of the output torque density versus $L_{\mathrm{m}}$ and $W_{\mathrm{m}}$. As can be found from Figure $7 \mathrm{a}$, the output torque density may increase with the growth of $L_{\mathrm{m}}$. As shown in Figure $7 \mathrm{~b}, W_{\mathrm{m}}$ is better to be designed as $10.5 \mathrm{~mm}$ to achieve a maximum output torque density.

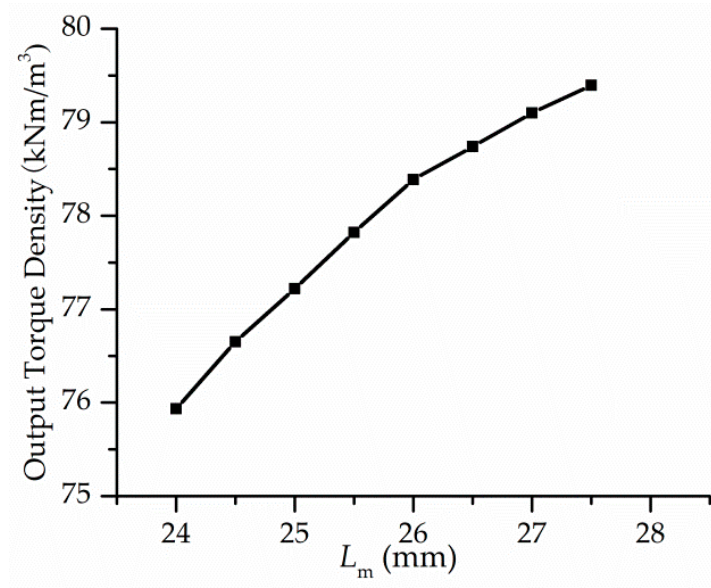

(a)

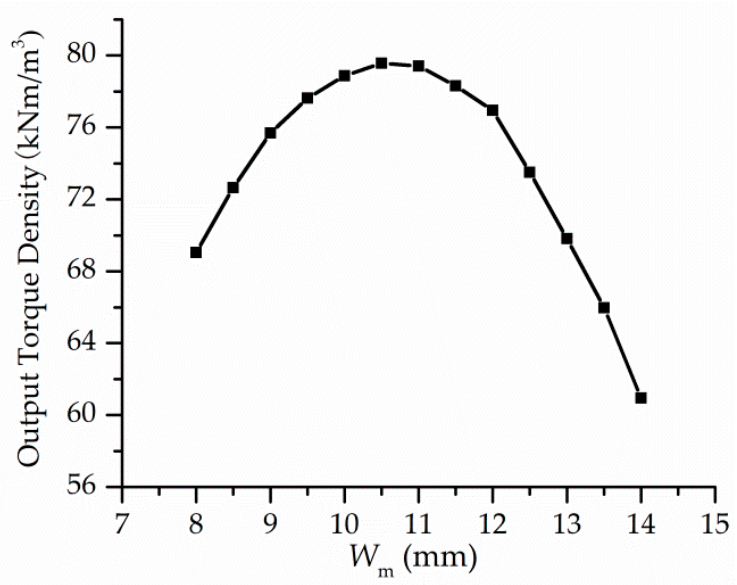

(b)

Figure 7. Output torque density curves versus $L_{\mathrm{m}}$ and $W_{\mathrm{m}}$. (a) Length of rectangular shape modulation pieces; (b) Width of rectangular shape modulation pieces.

\subsection{The Influence of the Inner Radius}

Because the outer radius $R_{\text {out }}$ of the HAMG is constant, the increase of $R_{\text {in }}$ inevitably leads to a reduction of the amount of PMs, which will surely reduce the output torque. The output torque density could not be used as a criterion for indicating the torque capability of the HAMG since the volume of the HAMG does not change with $R_{\text {in }}$. The trend of the output torque density curve will be as same as that of the output torque. The effective torque density, which is a ratio of the output torque to the effective volume of the HAMG, is proposed as a new indicator. The effective volume of the HAMG is just the volume of solid part. 
The influence of $R_{\text {in }}$ on the output torque and the effective torque density is illustrated in Figure 8. The output torque significantly decreases as $R_{\text {in }}$ increases. A $40 \mathrm{~mm}$ inner radius is chosen as the result of overall consideration of the effective torque density as well as dimensions of the bearings and shaft.

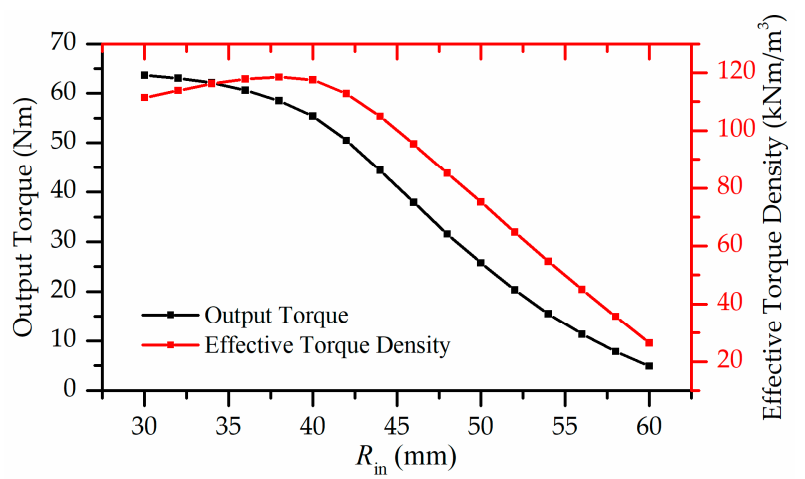

Figure 8. Output torque and effective torque density curves versus $R_{\mathrm{in}}$.

\subsection{The Influences of the Mechanical Angles of Each Axially Magnetized PMs of the Two Rotors}

The relationship between the mechanical angle of PMs per pole on the high-speed rotor $\omega_{\mathrm{h}}$ the mechanical angle of each axially magnetized PMs on the high-speed rotor $\theta_{\mathrm{h}}$, and the mechanical angle of PMs magnetized in other directions on the high-speed rotor $\tau_{\mathrm{h}}$ is,

$$
\tau_{\mathrm{h}}=\omega_{\mathrm{h}}-\theta_{\mathrm{h}}
$$

The relationship between the mechanical angle of PMs per pole on the low-speed rotor $\omega_{1}$, the mechanical angle of each axially magnetized PMs on the low-speed rotor $\theta_{1}$ and the mechanical angle of PMs magnetized in other directions on the low-speed rotor $\tau_{1}$ is,

$$
\tau_{1}=\omega_{1}-\theta_{1}
$$

The influences of $\theta_{\mathrm{h}}$ and $\theta_{\mathrm{l}}$ on the output torque density are shown in Figure $9 \mathrm{a}, \mathrm{b}$. The output torque density does not always increase with the increases of $\theta_{\mathrm{h}}$ and $\theta_{\mathrm{l}}$. The values of $\theta_{\mathrm{h}}$ and $\theta_{\mathrm{l}}$ are better to be selected at $17^{\circ}$ and $7^{\circ}$ to maximize the output torque density.

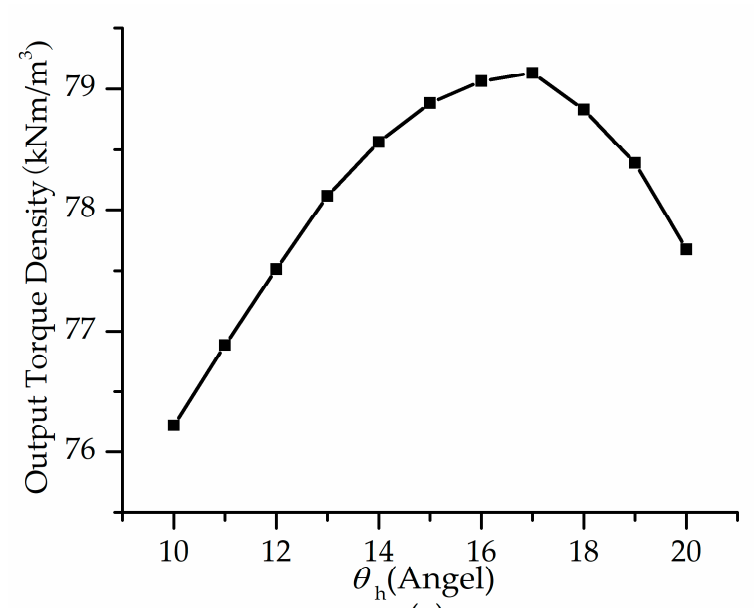

(a)

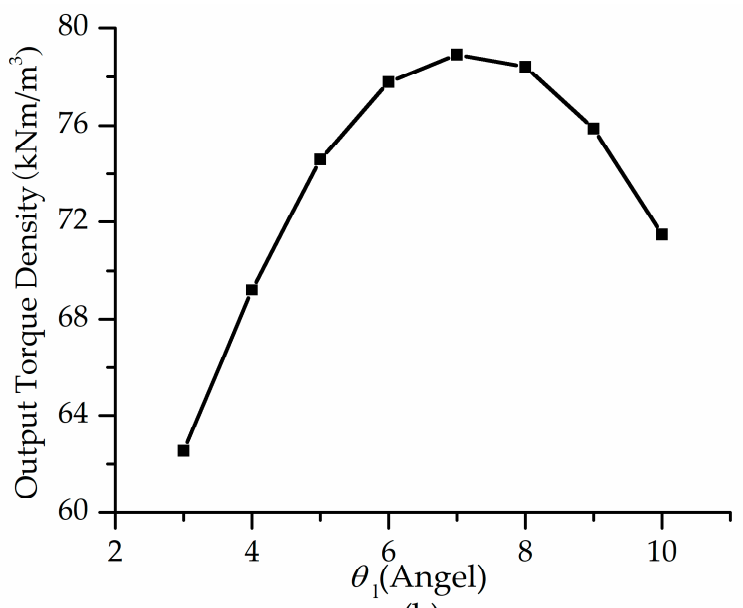

(b)

Figure 9. Output torque density curves versus $\theta_{\mathrm{h}}$ and $\theta_{\mathrm{l}}$. (a) Mechanical angle of each axially magnetized PMs on the high-speed rotor; (b) Mechanical angle of each axially magnetized PMs on the low-speed rotor. 


\section{Optimization of the HAMG}

After analyzing the effect of individual dimensional parameters on the torque capability of the HAMG, an optimization is carried out with comprehensive consideration of the interactions among all parameters simultaneously. During the optimization process, the parameters $R_{\text {out }}, R_{\mathrm{in}}$ and $T_{\mathrm{m}}$ are fixed as $70 \mathrm{~mm}, 40 \mathrm{~mm}$ and $8 \mathrm{~mm}$, respectively. Maximizing the output torque density is set as the optimization objective.

Maxwell software is adopted for the optimization. The optimal solution is found according to the flowchart given in Figure 10. The 3D FEM is used to compute the output torque density in order to enhance the solution accuracy. After more than 400 sets of data calculation, optimization has finally reached convergence. The parametric optimization constraints and results are obtained and listed in Table 6 . Moreover, Table 6 presents the comparison between parametric analysis and optimization. The results indicate that a good match is obtained between parametric analysis and optimization results.

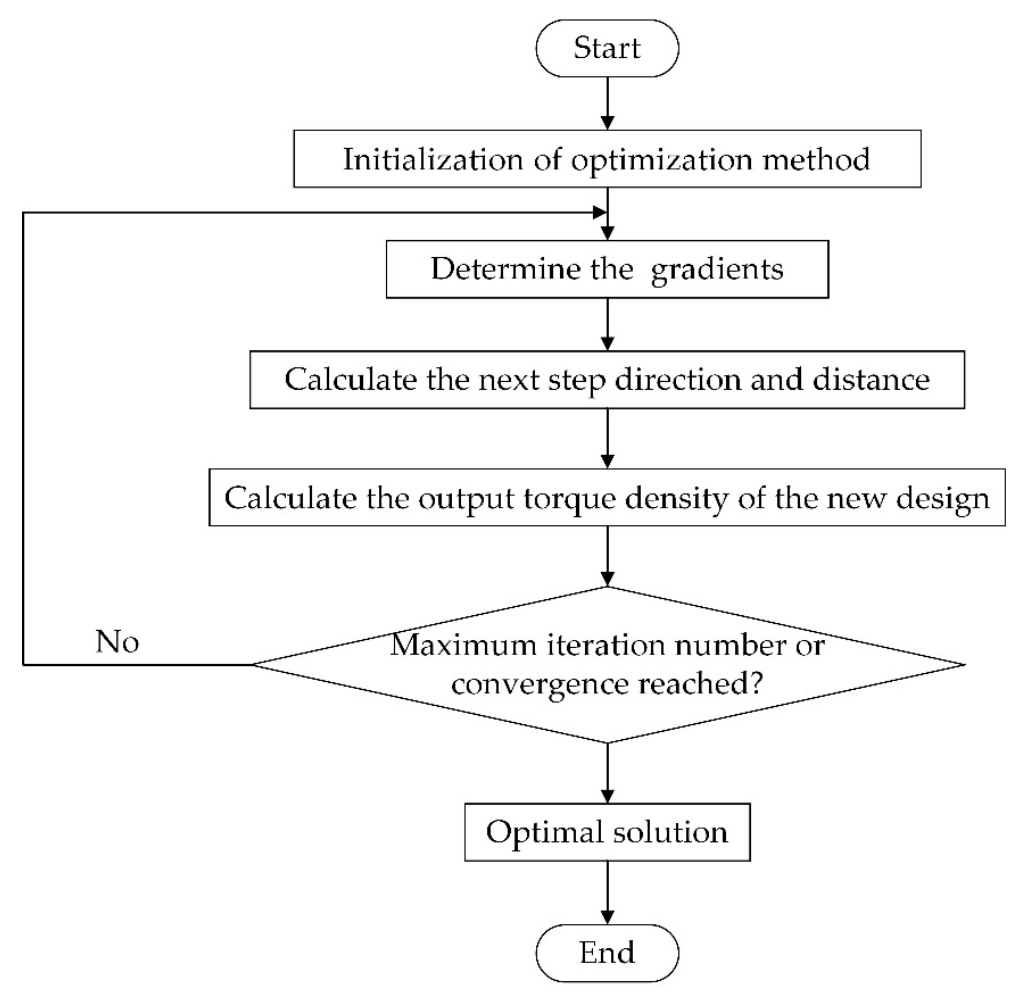

Figure 10. Procedure with the 3D FEM embedded in the optimization algorithm.

Table 6. Optimal parameters of the HAMG.

\begin{tabular}{cccc}
\hline Parameters & Restrictions & Optimization & Parametric Analysis \\
\hline$T_{\mathrm{h}}$ & $5-55 \mathrm{~mm}$ & $20.9 \mathrm{~mm}$ & $21 \mathrm{~mm}$ \\
$T_{1}$ & $5-23 \mathrm{~mm}$ & $11.1 \mathrm{~mm}$ & $11 \mathrm{~mm}$ \\
$L_{\mathrm{m}}$ & $24-27.5 \mathrm{~mm}$ & $27.5 \mathrm{~mm}$ & $27.5 \mathrm{~mm}$ \\
$W_{\mathrm{m}}$ & $8-14 \mathrm{~mm}$ & $10.5 \mathrm{~mm}$ & $10.5 \mathrm{~mm}$ \\
$\theta_{\mathrm{h}}$ & $10-20^{\circ}$ & $16.9 \mathrm{~mm}$ & $17^{\circ}$ \\
$\theta_{1}$ & $3-10^{\circ}$ & $6.9 \mathrm{~mm}$ & $7^{\circ}$ \\
\hline
\end{tabular}

In order to explain the high torque capability of the optimized HAMG in depth, spectrum analysis is presented based on the second simplified torque calculation formulas. Figures 11-15 show the FFT analysis of the axial and tangential flux densities at the radii of $R_{\mathrm{m} 1}, R_{\mathrm{m} 2}, R_{\mathrm{m} 3}, R_{\mathrm{m} 4}$ and $R_{\mathrm{m} 5}$ in the LG of the HAMG. It could be shown that the amplitudes of 4th-, 13th-, 21st- and 47th-order harmonics of the axial flux densities and the amplitudes of 4th-, 21st- and 38th-order harmonics of the tangential 
flux densities at the radii of $R_{\mathrm{m} 1}, R_{\mathrm{m} 2}, R_{\mathrm{m} 3}, R_{\mathrm{m} 4}$ and $R_{\mathrm{m} 5}$ in the $\mathrm{LG}$ are all improved by optimization in different degree.

The output torques of the initial and optimized HAMG obtained by the 3D FEM are $54.7 \mathrm{Nm}$ and $82.6 \mathrm{Nm}$, respectively. The output torque has an increase of $51 \%$ by optimization. The initial and optimized output torques obtained by the second simplified calculation method are $55.8 \mathrm{Nm}$ and $84.6 \mathrm{Nm}$, which are $2.0 \%$ and $2.4 \%$ larger than the torques obtained by the 3D FEM. Tables 7-11 list the magnitudes of the axial and tangential flux densities of dominating harmonics, their phase differences and generated torque due to the dominant harmonics. The output torque of the HAMG is mainly generated by 13th-order harmonic. Table 7 shows that the algebraic value of $b_{z}^{13} b_{\theta}^{13}$ at the radius of $R_{\mathrm{m} 1}$ is improved from 0.368 to 0.389 by optimization with an increase of $5.7 \%$, while the algebraic value of $\cos \left(\varphi_{\mathrm{Z}}^{13}-\varphi_{\theta}^{13}\right)$ is improved from 0.598 to 0.795 with a significant increase of $33 \%$. Table 8 shows that the algebraic value of $b_{z}^{13} b_{\theta}^{13}$ at the radius of $R_{\mathrm{m} 2}$ is improved from 0.623 to 0.664 by optimization with an increase of $6.6 \%$, while the algebraic value of $\cos \left(\varphi_{\mathrm{z}}^{13}-\varphi_{\theta}^{13}\right)$ is improved from 0.615 to 0.837 with a significant increase of $36 \%$. Table 9 shows that the algebraic value of $b_{z}^{13} b_{\theta}^{13}$ at the radius of $R_{\mathrm{m} 3}$ is improved from 0.629 to 0.663 by optimization with an increase of $5.4 \%$, while the algebraic value of $\cos \left(\varphi_{\mathrm{Z}}^{13}-\varphi_{\theta}^{13}\right)$ is improved from 0.429 to 0.612 with a significant increase of $43 \%$. Table 10 shows that the algebraic value of $b_{z}^{13} b_{\theta}^{13}$ at the radius of $R_{\mathrm{m} 4}$ is improved from 0.551 to 0.583 by optimization with an increase of $5.8 \%$, while the algebraic value of $\cos \left(\varphi_{\mathrm{z}}^{13}-\varphi_{\theta}^{13}\right)$ is improved from 0.311 to 0.463 with a significant increase of $49 \%$. Table 11 shows that the algebraic value of $b_{z}^{13} b_{\theta}^{13}$ at the radius of $R_{\mathrm{m} 5}$ is improved from 0.313 to 0.339 by optimization with an increase of $8.3 \%$, while the algebraic value of $\cos \left(\varphi_{\mathrm{z}}^{13}-\varphi_{\theta}^{13}\right)$ is improved from 0.350 to 0.521 with a significant increase of $49 \%$. Therefore, the increase in output torque of the HAMG by optimization is mainly caused by the increase of the phase difference of 13th order harmonic. The initial and optimized volumes of the HAMG are 700 $\mathrm{cm}^{3}$ and $885 \mathrm{~cm}^{3}$, respectively. As a result, the output torque density of the HAMG is improved from $78.1 \mathrm{kNm} / \mathrm{m}^{3}$ to $93.3 \mathrm{kNm} / \mathrm{m}^{3}$ by optimization with an increase of $19 \%$.
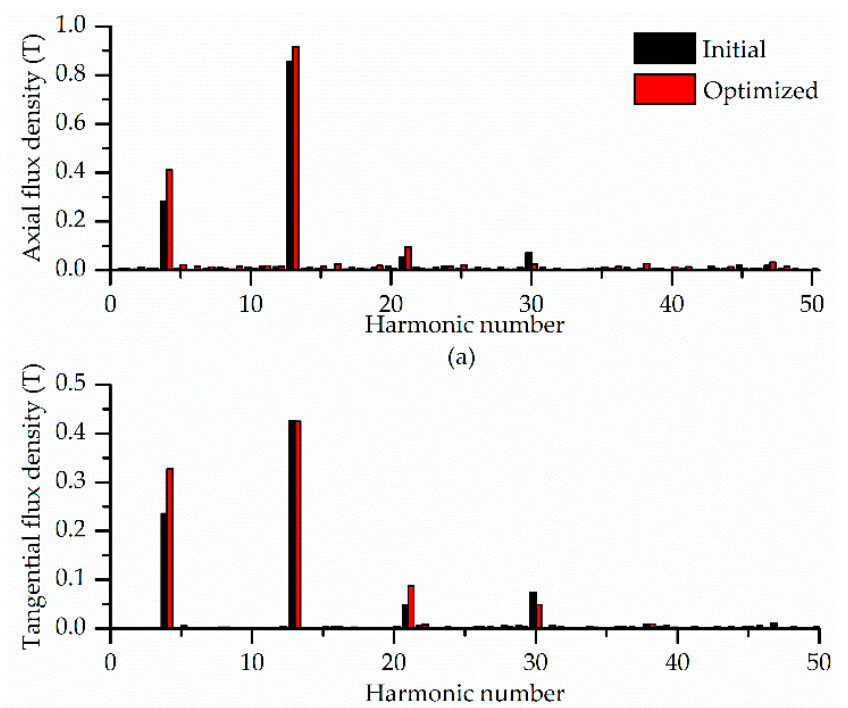

(b)

Figure 11. Fast Fourier transformation (FFT) analysis of the axial and tangential flux densities at the radius of $R_{\mathrm{m} 1}$ in the air gap adjacent to the low-speed rotor (LG) of the HAMG. (a) Axial flux density; (b) Tangential flux density. 

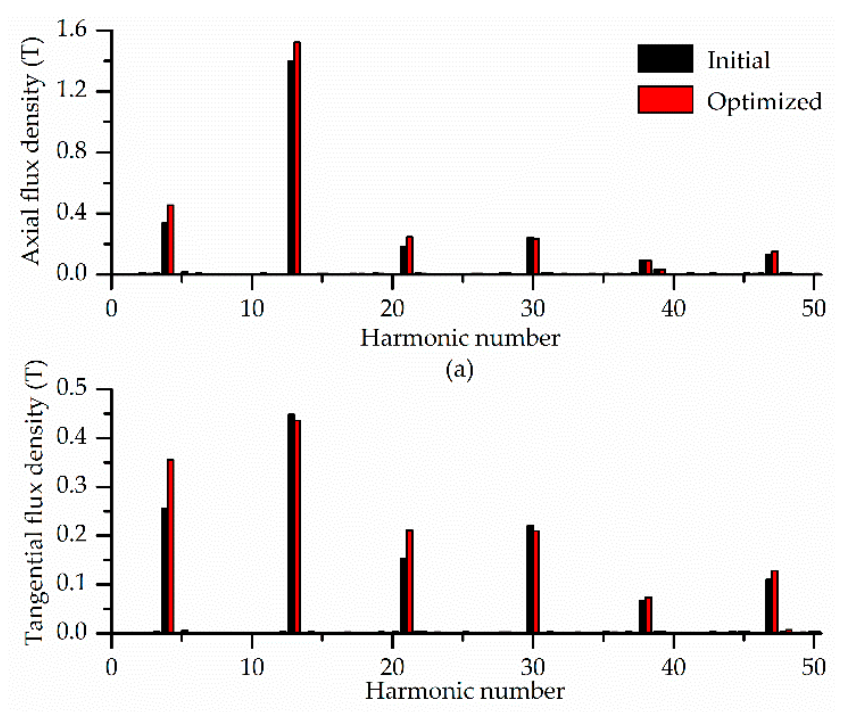

(b)

Figure 12. FFT analysis of the axial and tangential flux densities at the radius of $R_{\mathrm{m} 2}$ in the LG of the HAMG. (a) Axial flux density; (b) Tangential flux density.

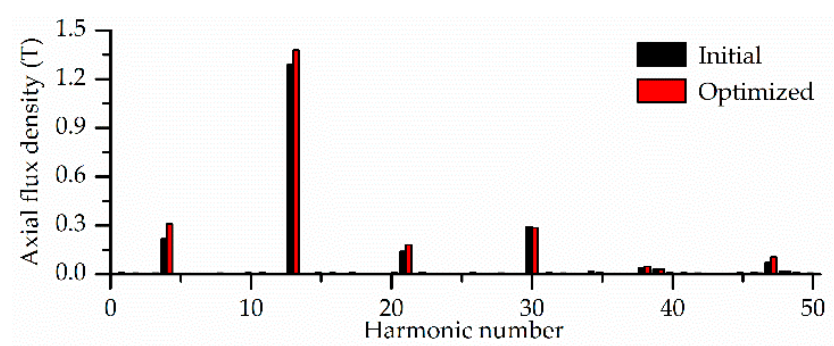

(a)

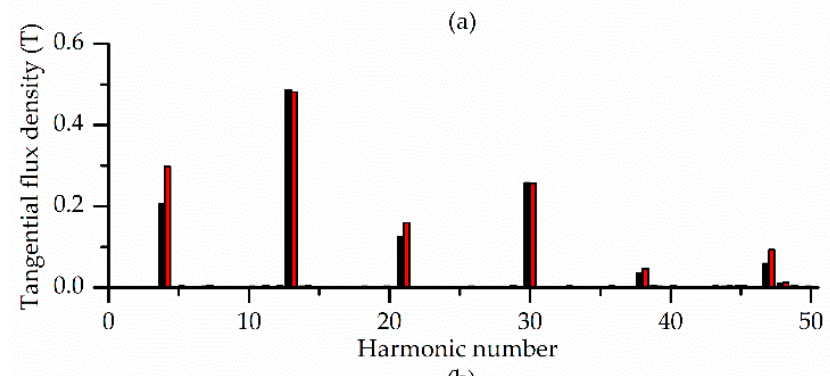

(b)

Figure 13. FFT analysis of the axial and tangential flux densities at the radius of $R_{\mathrm{m} 3}$ in the LG of the HAMG. (a) Axial flux density; (b) Tangential flux density. 

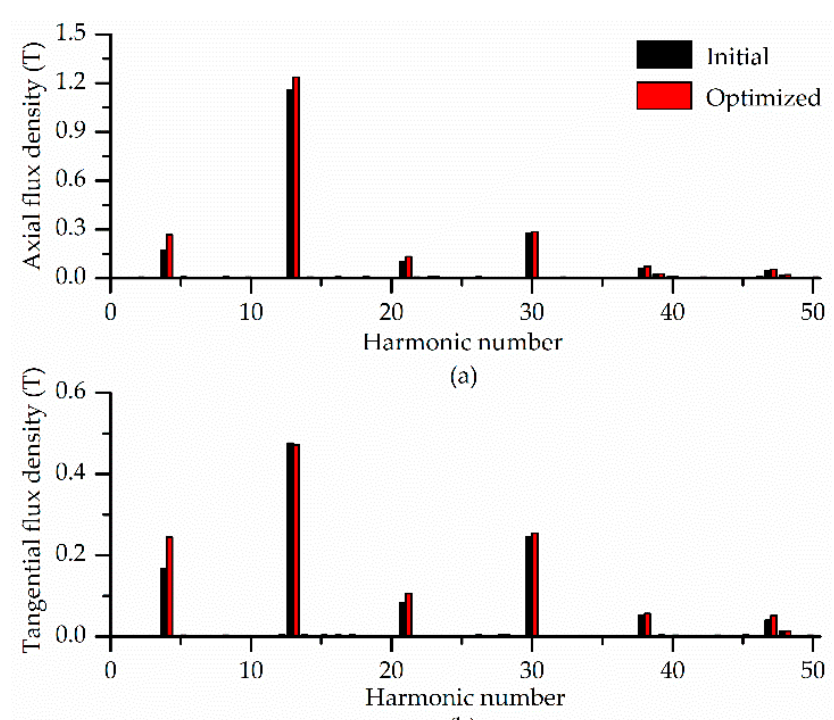

(b)

Figure 14. FFT analysis of the axial and tangential flux densities at the radius of $R_{\mathrm{m} 4}$ in the LG of the HAMG. (a) Axial flux density; (b) Tangential flux density.

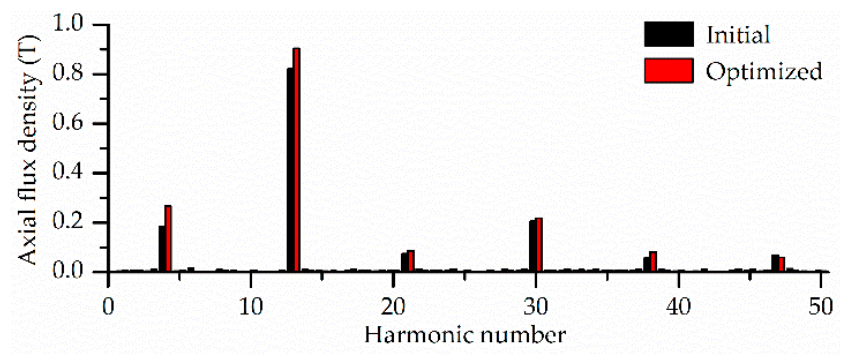

(a)

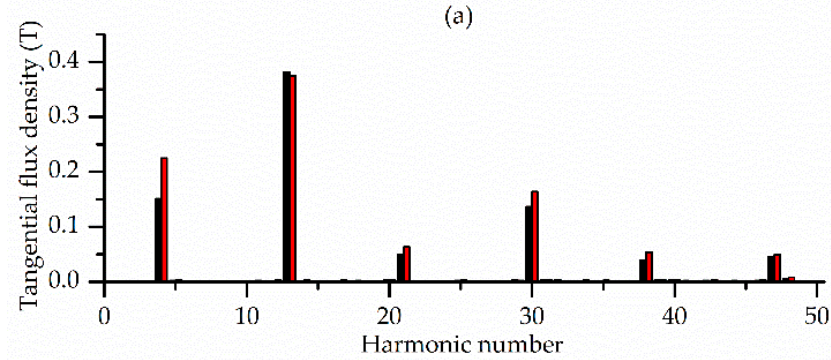

(b)

Figure 15. FFT analysis of the axial and tangential flux densities at the radius of $R_{\mathrm{m} 5}$ in the LG of the HAMG. (a) Axial flux density; (b) Tangential flux density. 
Table 7. Amplitudes, the phase differences and torque due to the air-gap flux density at the radius of $R_{\mathrm{m} 1}$.

\begin{tabular}{|c|c|c|c|c|c|}
\hline \multicolumn{2}{|c|}{ Harmonic Order } & $b_{z}^{n} / \mathrm{T}$ & $b_{\theta}^{n} / \mathrm{T}$ & $\varphi_{z}^{n}-\varphi_{\theta}^{n} /^{\circ}$ & Torque/Nm \\
\hline \multirow{2}{*}{ 4th } & Initial Design & 0.282 & 0.235 & 82.4 & 0.0760 \\
\hline & $\begin{array}{l}\text { Optimized } \\
\text { Design }\end{array}$ & 0.412 & 0.328 & 76.9 & 0.257 \\
\hline \multirow{2}{*}{ 13th } & Initial Design & 0.859 & 0.428 & 53.3 & 1.85 \\
\hline & $\begin{array}{l}\text { Optimized } \\
\text { Design }\end{array}$ & 0.916 & 0.425 & 37.4 & 2.60 \\
\hline \multirow{2}{*}{ 21st } & Initial Design & 0.0530 & 0.0470 & 166 & -0.0200 \\
\hline & $\begin{array}{l}\text { Optimized } \\
\text { Design }\end{array}$ & 0.0950 & 0.0870 & 124 & -0.0390 \\
\hline \multirow{2}{*}{ 30th } & Initial Design & 0.0720 & 0.0740 & 44.0 & 0.0320 \\
\hline & $\begin{array}{l}\text { Optimized } \\
\text { Design }\end{array}$ & 0.0260 & 0.0490 & 10.7 & 0.0100 \\
\hline
\end{tabular}

Table 8. Amplitudes, the phase differences and torque due to the air-gap flux density at the radius of $R_{\mathrm{m} 2}$.

\begin{tabular}{|c|c|c|c|c|c|}
\hline \multicolumn{2}{|c|}{ Harmonic Order } & \multirow{2}{*}{$\begin{array}{l}\boldsymbol{b}_{z}^{n} / \mathrm{T} \\
0.326\end{array}$} & \multirow{2}{*}{$\begin{array}{l}b_{\theta}^{n} / \mathrm{T} \\
0.256\end{array}$} & \multirow{2}{*}{$\begin{array}{c}\frac{\varphi_{z}^{n}-\varphi_{\theta}^{n} /{ }^{\circ}}{82.1} \\
\end{array}$} & \multirow{2}{*}{$\begin{array}{c}\text { Torque/Nm } \\
0.0410\end{array}$} \\
\hline & Initial Design & & & & \\
\hline 4th & $\begin{array}{l}\text { Optimized } \\
\text { Design }\end{array}$ & 0.455 & 0.356 & 82.6 & 0.882 \\
\hline \multirow{2}{*}{ 13th } & Initial Design & 1.39 & 0.448 & 52.1 & 16.2 \\
\hline & $\begin{array}{l}\text { Optimized } \\
\text { Design }\end{array}$ & 1.52 & 0.436 & 33.1 & 23.5 \\
\hline \multirow{2}{*}{ 21st } & Initial Design & 0.183 & 0.153 & 92.6 & -0.0540 \\
\hline & $\begin{array}{l}\text { Optimized } \\
\text { Design }\end{array}$ & 0.246 & 0.211 & 92.3 & -0.0900 \\
\hline \multirow{2}{*}{ 30th } & Initial Design & 0.242 & 0.220 & 92.7 & -0.106 \\
\hline & $\begin{array}{l}\text { Optimized } \\
\text { Design }\end{array}$ & 0.234 & 0.210 & 95.2 & -0.188 \\
\hline
\end{tabular}

Table 9. Amplitudes, phase differences and torque due to the air-gap flux density at the radius of $R_{\mathrm{m} 3}$.

\begin{tabular}{cccccc}
\hline \multicolumn{2}{c}{ Harmonic Order } & $\boldsymbol{b}_{z}^{n} / \mathbf{T}$ & $\boldsymbol{b}_{\theta}^{n} / \mathbf{T}$ & $\boldsymbol{\varphi}_{z}^{n}-\boldsymbol{\varphi}_{\theta}^{n} /{ }^{\circ}$ & Torque/Nm \\
\hline \multirow{2}{*}{ th } & $\begin{array}{c}\text { Initial Design } \\
\text { Optimized } \\
\text { Design }\end{array}$ & 0.227 & 0.203 & 89.6 & 0.0250 \\
& 0.31 & 0.298 & 89.7 & 0.0410 \\
\hline \multirow{2}{*}{ 3th } & $\begin{array}{c}\text { Initial Design } \\
\text { Optimized } \\
\text { 21st }\end{array}$ & 1.29 & 0.487 & 64.6 & 20.4 \\
& Design & 1.38 & 0.481 & 52.2 & 30.7 \\
\hline \multirow{2}{*}{ 30th } & $\begin{array}{c}\text { Initial Design } \\
\text { Optimized } \\
\text { Design }\end{array}$ & 0.140 & 0.124 & 88.3 & 0.0390 \\
& $\begin{array}{c}\text { Initial Design } \\
\text { Optimized } \\
\text { Design }\end{array}$ & 0.180 & 0.159 & 89.3 & 0.0250 \\
\hline & 0.285 & 0.258 & 88.9 & 0.107 \\
\hline
\end{tabular}


Table 10. Amplitudes, phase differences and torque due to the air-gap flux density at the radius of $R_{\mathrm{m} 4}$.

\begin{tabular}{|c|c|c|c|c|c|}
\hline \multicolumn{2}{|c|}{ Harmonic Order } & \multirow{2}{*}{$\begin{array}{l}b_{z}^{n} / \mathrm{T} \\
0.172\end{array}$} & \multirow{2}{*}{$\begin{array}{l}b_{\theta}^{n} / \mathrm{T} \\
0.165\end{array}$} & \multirow{2}{*}{$\frac{\varphi_{z}^{n}-\varphi_{\theta}^{n} /^{\circ}}{76.9}$} & \multirow{2}{*}{$\begin{array}{c}\text { Torque/Nm } \\
0.528\end{array}$} \\
\hline & Initial Design & & & & \\
\hline 4 th & $\begin{array}{l}\text { Optimized } \\
\text { Design }\end{array}$ & 0.269 & 0.244 & 79.4 & 0.989 \\
\hline \multirow{2}{*}{ 13th } & Initial Design & 1.16 & 0.475 & 71.9 & 14.0 \\
\hline & $\begin{array}{l}\text { Optimized } \\
\text { Design }\end{array}$ & 1.24 & 0.471 & 62.4 & 22.1 \\
\hline \multirow{2}{*}{ 21st } & Initial Design & 0.100 & 0.0830 & 91.6 & -0.0190 \\
\hline & $\begin{array}{l}\text { Optimized } \\
\text { Design }\end{array}$ & 0.133 & 0.106 & 84.9 & 0.101 \\
\hline \multirow{2}{*}{ 30th } & Initial Design & 0.277 & 0.246 & 90.1 & -0.0130 \\
\hline & $\begin{array}{l}\text { Optimized } \\
\text { Design }\end{array}$ & 0.285 & 0.254 & 90.9 & -0.0910 \\
\hline
\end{tabular}

Table 11. Amplitudes, the phase differences and torque due to the air-gap flux density at the radius of $R_{\mathrm{m} 5}$.

\begin{tabular}{|c|c|c|c|c|c|}
\hline \multicolumn{2}{|c|}{ Harmonic Order } & \multirow{2}{*}{$\begin{array}{l}\boldsymbol{b}_{z}^{n} / \mathrm{T} \\
0.174\end{array}$} & \multirow{2}{*}{$\begin{array}{l}\boldsymbol{b}_{\boldsymbol{\theta}}^{\boldsymbol{n}} / \mathrm{T} \\
0.151\end{array}$} & \multirow{2}{*}{$\frac{\varphi_{z}^{n}-\varphi_{\theta}^{n} /^{\circ}}{83.4}$} & \multirow{2}{*}{$\begin{array}{c}\text { Torque/Nm } \\
0.0720\end{array}$} \\
\hline & Initial Design & & & & \\
\hline 4th & $\begin{array}{l}\text { Optimized } \\
\text { Design }\end{array}$ & 0.267 & 0.225 & 84.2 & 0.146 \\
\hline \multirow{2}{*}{ 13th } & Initial Design & 0.839 & 0.373 & 69.5 & 2.61 \\
\hline & $\begin{array}{l}\text { Optimized } \\
\text { Design }\end{array}$ & 0.904 & 0.375 & 58.6 & 4.20 \\
\hline \multirow{2}{*}{ 21st } & Initial Design & 0.0740 & 0.0500 & 76.5 & 0.0210 \\
\hline & $\begin{array}{l}\text { Optimized } \\
\text { Design }\end{array}$ & 0.0860 & 0.0640 & 88.0 & 0.00500 \\
\hline \multirow{2}{*}{ 30th } & Initial Design & 0.205 & 0.137 & 86.7 & 0.0380 \\
\hline & $\begin{array}{l}\text { Optimized } \\
\text { Design }\end{array}$ & 0.218 & 0.164 & 84.0 & 0.0890 \\
\hline
\end{tabular}

\section{Conclusions}

In this paper, torque and axial force calculation formulas are proposed based on the air-gap flux density distribution. Because of the difference of the air-gap flux densities at different radii, two simplified torque and axial force calculation formulas are proposed and compared. The accuracy of the second simplified torque and axial force calculation method is much higher than the first simplified torque and axial force calculation method.

The influence of individual dimensional parameters on the torque capability of the HAMG is investigated. To maximize the output torque density, Maxwell software is used to carry out the optimization with the aid of the 3D FEM. Six parameters, i.e., $T_{\mathrm{h}}, T_{1}, R_{\mathrm{in}}, T_{\mathrm{m}}, W_{\mathrm{m}}$ and $\theta_{1}$, play important roles in torque generation of the HAMG. Details are as follows:

1. The output torque density of the HAMG increases first and then decreases as $T_{\mathrm{h}}, T_{1}, T_{\mathrm{m}}, W_{\mathrm{m}}$ and $\theta_{1}$ increase;

2. The output torque density of the HAMG significantly decreases as $R_{\mathrm{in}}$ increases;

3. $T_{\mathrm{h}}, T_{1}$ and $R_{\mathrm{in}}$ have more significant impacts on the output torque density of the HAMG than others.

Therefore, the amount of PMs is most important for the output torque density of the HAMG.

By carrying out the optimization, the output torque density of the HAMG has an increase of $19 \%$. By spectrum analysis, the increase in output torque by optimization is mainly caused by the phase difference of 13th-order harmonic. The torque and axial force calculation formulas, the influence of 
individual dimensional parameters on the torque capability and the reason for the increase in output torque by optimization could be applied to the same type of HAMG.

Author Contributions: Conceptualization, F.H. and X.L.; methodology, F.H.; software, Y.Z. and H.C.; validation, Y.Z., H.C. and X.L.; investigation, Y.Z. and X.L.; resources, F.H.; writing-original draft preparation, F.H. and Y.Z.; writing-review and editing, L.X. and Y.Z.; project administration, F.H.

Funding: This research was supported by the National Key R\&D Program of China (Grant No. 2018YFB0606000).

Conflicts of Interest: The authors declare no conflict of interest.

\section{References}

1. Atallah, K.; Howe, D. A novel high-performance magnetic gear. IEEE Trans. Magn. 2001, 37, 2844-2846. [CrossRef]

2. Liu, X.; Chau, K.T.; Jiang, J.Z.; Yu, C. Design and analysis of interior-magnet outer-rotor concentric magnetic gears. J. Appl. Phys. 2009, 105, 07F101. [CrossRef]

3. Chau, K.T.; Zhang, D.; Jiang, J.Z.; Liu, C.; Zhang, Y.J. Design of a magnetic-geared outer-rotor permanent magnet brushless motor for electric vehicles. IEEE Trans. Magn. 2007, 43, 2504-2506. [CrossRef]

4. Chau, K.T.; Chan, C.C.; Liu, C. Overview of permanent-magnet brushless drives for electric and hybrid electric vehicles. IEEE Trans. Ind. Electron. 2008, 55, 2246-2257. [CrossRef]

5. Jian, L.; Chau, K.T.; Jiang, J.Z. A magnetic-geared outer-rotor permanent-magnet brushless machine for wind power generation. IEEE Trans. Ind. Appl. 2009, 45, 954-962. [CrossRef]

6. Atallah, K.; Wang, J.; Howe, D. A high-performance linear magnetic gear. J. Appl. Phys. 2005, 97. [CrossRef]

7. Bird, J.; Li, K.; Williams, W.; Kadel, J. A flux focusing cycloidal magnetic gearbox. IEEE Trans. Magn. 2015, $51,1-4$.

8. Rens, J.; Atallah, K.; Calverley, S.D.; Howe, D. A novel magnetic harmonic gear. IEEE Trans. Ind. Appl. 2010, 46, 206-212. [CrossRef]

9. Mezani, S.; Atallah, K.; Howe, D. A high-performance axial-field magnetic gear. J. Appl. Phys. 2006, 99. [CrossRef]

10. Acharya, V.M.; Bird, J.Z.; Calvin, M. A Flux Focusing Axial Magnetic Gear. IEEE Trans. Magn. 2013, 49, 4092-4095. [CrossRef]

11. Tsai, M.; Ku, L. 3-D Printing-Based design of axial flux magnetic gear for high torque density. IEEE Trans. Magn. 2015, 51, 1-4. [CrossRef]

12. Johnson, M.; Gardner, M.C.; Toliyat, H.A. Analysis of axial field magnetic gears with Halbach arrays. Proc. IEEE Int. Elect. Mach. Drives Conf. 2015, 108-114.

13. Matthew, G.; Matthew, J.; Toliyat, H.A. Comparison of surface permanent magnet axial and radial flux coaxial magnetic gears. IEEE Trans. Energy Convers. 2018, 33, 2250-2259.

14. Johnson, M.; Gardner, M.C.; Toliyat, H.A. Design and analysis of an axial flux magnetically geared generator. IEEE Trans. Ind. Appl. 2017, 53, 97-105. [CrossRef]

15. Dong, K.; Yu, H. Study of an axial-flux modulated superconducting magnetic gear. IEEE Trans. Appl. Supercond. 2019, 29. [CrossRef]

16. Zhang, X.; Liu, X.; Chen, Z. A novel dual-flux-modulator coaxial magnetic gear for high torque capability. IEEE Trans. Energy Convers. 2018, 33, 682-691. [CrossRef]

17. Evans, D.J.; Zhu, Z.Q. Influence of design parameters on magnetic gear's torque capability. Proc. IEEE Int. Elect. Mach. Drives Conf. 2011, 1403-1408. [CrossRef]

(C) 2019 by the authors. Licensee MDPI, Basel, Switzerland. This article is an open access article distributed under the terms and conditions of the Creative Commons Attribution (CC BY) license (http://creativecommons.org/licenses/by/4.0/). 